\title{
Does thermoregulatory behavior maximize reproductive fitness of natural isolates of Caenorhabditis elegans?
}

\author{
Jennifer L Anderson ${ }^{1 \dagger}$, Lori Albergotti ${ }^{1,4+}$, Barbara Ellebracht ${ }^{2}$, Raymond B Huey ${ }^{3}$ and Patrick C Phillips ${ }^{1 *}$
}

\begin{abstract}
Background: A central premise of physiological ecology is that an animal's preferred body temperature should correspond closely with the temperature maximizing performance and Darwinian fitness. Testing this coadaptational hypothesis has been problematic for several reasons. First, reproductive fitness is the appropriate measure, but is difficult to measure in most animals. Second, no single fitness measure applies to all demographic situations, complicating interpretations. Here we test the co-adaptation hypothesis by studying an organism (Caenorhabditis elegans) in which both fitness and thermal preference can be reliably measured.

Results: We find that natural isolates of $C$. elegans display a range of mean thermal preferences and also vary in their thermal sensitivities for fitness. Hot-seeking isolates CB4854 and CB4857 prefer temperatures that favor population growth rate $(r)$, whereas the cold-seeking isolate CB4856 prefers temperatures that favor Lifetime Reproductive Success (LRS).

Conclusions: Correlations between fitness and thermal preference in natural isolates of C. elegans are driven primarily by isolate-specific differences in thermal preference. If these differences are the result of natural selection, then this suggests that the appropriate measure of fitness for use in evolutionary ecology studies might differ even within species, depending on the unique ecological and evolutionary history of each population.
\end{abstract}

\section{Background}

How organisms respond to environmental variation and change, both in the short term via mechanisms such as behavior modulation and in the long term via evolutionary changes in features such as the pattern of reproductive allocation, remains a central question in ecology and evolutionary biology. Temperature variation in particular has profound effects on the physiology, ecology, and fitness of ectotherms [1-5]. Extreme temperatures are injurious and potentially lethal, but even temperatures within lethal limits dramatically change performance and ultimately Darwinian fitness $[3,6,7]$. Even so, most ectotherms are not at the mercy of the thermal environment but rely on behavioral adjustments ([8], but see [9]) to regulate body temperatures at usually

\footnotetext{
* Correspondence: pphil@uoregon.edu

+ Contributed equally

'Center for Ecology and Evolutionary Biology, University of Oregon, Eugene, OR 97402, USA

Full list of author information is available at the end of the article
}

narrow, species-specific levels. These behaviors are thought to be adaptive in two complementary ways. (i) They help animals avoid extreme temperatures that can be damaging or lethal $[10,11]$. (ii) They increase the time spent at physiologically optimal temperatures, thus enhancing overall physiological performance and survival in nature [10,12-17]. For these reasons, thermal preferences are widely assumed to maximize Darwinian fitness [18].

More formally, a long-standing adaptive hypothesis proposes that behavior and physiology co-evolve, such that thermal preferences should be centered at or near temperatures that maximize fitness (Figure 1A) [12,18-21]. These temperatures are often called "preferred body temperatures" $\left(T_{p}\right)$ and are estimated in the laboratory via thermal gradients [22]. Previous approaches to testing this classical coadaptation hypothesis reveal that preferred body temperatures often correlate with optimal temperatures for various performance traits, though generally not 1:1 [6]. In any case, these tests are not ideal because they
C Biomed Central

() 2011 Anderson et al; licensee BioMed Central Ltd. This is an Open Access article distributed under the terms of the Creative Commons Attribution License (http://creativecommons.org/licenses/by/2.0), which permits unrestricted use, distribution, and reproduction in any medium, provided the original work is properly cited. 


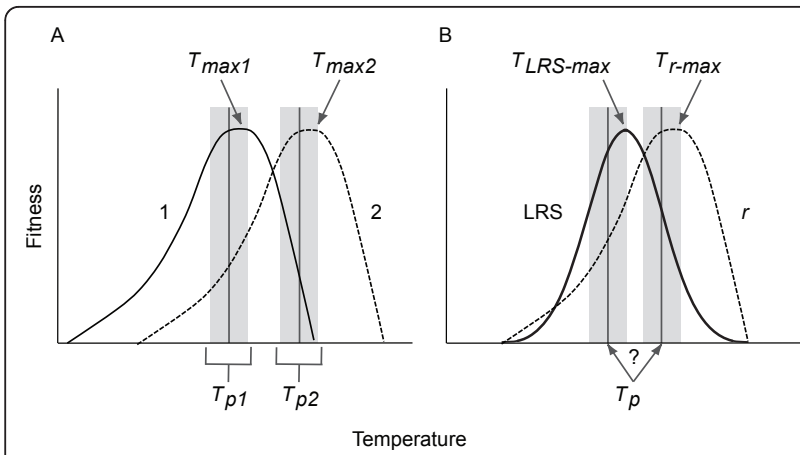

Figure 1 Expected coevolution of thermal preference and fitness. Under the coadaptation hypothesis, organisms are expected to prefer a narrow range of temperatures $\left(T_{p}\right)$ that corresponds to, but is slightly lower than [6], body temperatures that maximize their fitness $\left(T_{\text {max }}\right)$. A) If this hypothesis is valid, populations with relatively high $T_{p}$ will have relatively high $T_{\max }$ as depicted here. B) However, the thermal sensitivity of Lifetime Reproductive Success (LRS) is generally shifted to a lower temperature than that maximizing the intrinsic rate of increase ( $r$ ) (see [3]); thus, the $T_{p}$ of a given population can correspond with $T_{L R S-\max }$ or $T_{r-\max }$.

use performance (e.g. traits such as sprint speed and digestion $[2,18,19,23,24])$ as a proxy for fitness. The reason for using fitness proxies is obvious: estimating fitness at multiple temperatures is extremely difficult with most ectotherms. Nevertheless, although performance influences fitness, it is not fitness [25-27]. Furthermore, although interspecific comparisons are important, intraspecific level tests of this hypothesis are especially informative because such comparisons are less likely to be confounded by other inter-species differences and potentially more likely to be the result of adaptation to the local environment (i.e. be tied to fitness differences between populations). Thus, an advance in testing the co-adaptational hypothesis would involve examining the relationship between thermal preference and the temperatures maximizing Darwinian fitness in a species that shows intraspecific variation in thermal preference and in which the thermal dependence of fitness can be readily and reliably estimated.

According to the co-adaptational hypothesis, population mean fitness would be maximized if all individuals in a population thermoregulate perfectly: if so, individuals will prefer and experience only the narrow range of temperatures that results in the highest fitness (but see [6]). However, organisms - either in laboratory thermal gradients or in nature - at least temporarily occupy a range of temperatures. From the coadaptation hypothesis, it naturally follows that such imperfect thermoregulation will impose a fitness cost or decrement. Regardless of whether distribution of individuals on a thermal gradient is due to underlying variation in preferred temperature or the transient occupation of different temperatures within a range of preferred or non-lethal temperatures, deviations from the optimal fitness temperature should lower population mean fitness, generating a "performance load" on the population (sensu $[28,29])$. Thus a corollary to the thermal coadaptation hypothesis is that natural selection should act to decrease the performance load of a population under environmental conditions in which variation in performance has its largest effect on overall fitness.

A complication in testing the relationship between thermal preference and Darwinian fitness is that the appropriate measure of fitness differs depending on the specific demographic context of the population involved. Fitness is commonly estimated either as reproductive output, $R_{\mathrm{o}}$ [or its individual level equivalent Lifetime Reproductive Success (LRS), the total number of offspring produced during a female's lifetime] or as the intrinsic rate of population increase $(r)$, which is influenced both by offspring number and reproductive timing. Because $r$ is strongly and inversely related to generation time [30], which decreases with temperature in ectotherms, temperatures that maximize $r$ are generally higher than those that maximize rate-insensitive fitness metrics $R_{\mathrm{o}}$ and LRS (Figure 1B) [3]. Thus, thermal preference behaviors can maximize $R_{\mathrm{o}}$ (or LRS) or $r$, but not both simultaneously (Figure $1 \mathrm{~B}$ ). The question then becomes which measure of fitness should correspond with thermal preference? Evolutionary ecologists [31-35] have suggested that the relevant fitness measure can be identified using basic demographic information (e.g. knowing whether the population is stable or expanding, or has discrete or overlapping generations). However, these factors are frequently unknown for natural populations, making a priori identification of the appropriate fitness metric impossible.

Here we study thermal coadaptation in Caenorhabditis elegans. These nematodes are very small $(\sim 1 \mathrm{~mm}$ as adults) and are easily maintained in the laboratory [36]. Consequently, the distribution and $T_{p}$ of large numbers of individuals can be determined on controlled thermal gradients. Moreover, fitness (e.g. [37-41]) - and specifically the thermal dependence of fitness [42-44] - can also be repeatedly and reliably estimated in C. elegans. Although the demographic status of these worms is unknown, both LRS and $r$ are readily estimable in this system: thus we can examine the relationship between thermal preference and both fitness metrics. Accordingly, we determined the $T_{p}$ and the thermal dependence of both fitness measures for eight natural isolates of $C$. elegans and then explored whether $T_{p}$ corresponds with temperatures that maximize fitness.

\section{Methods}

\section{Thermal preference and fitness assays}

Natural isolates of Caenorhabditis elegans $(\mathrm{N}=8$, Table 1) were obtained from the Caenorhabditis 


\begin{tabular}{ll}
$\begin{array}{l}\text { Table } \mathbf{1} \text { Geographic origin of C.elegans natural isolates } \\
\text { used in this study }\end{array}$ \\
\hline Strain & Origin \\
\hline AB3 & Adelaide, Australia \\
CB4854 & Altadena, CA, USA \\
CB4855 & Palo Alto, CA, USA \\
CB4856 & Hawaii, USA \\
CB4857 & Claremont, CA, USA \\
JU258 & Fibeiro Frio, Madeira \\
JU262 & Le Blanc, France \\
PX174 & - -
\end{tabular}

*Based on genomic information [54] PX174 appears to be a lab derived subisolate of RC301, which is from Freiburg, Germany.

Genetics Center (University of Minnesota, Minneapolis, $\mathrm{MN}$ ), inbred for 10 generations, and immediately frozen to minimize further genetic changes. Stocks of these inbred lines were allowed to recover from freezing for at least two generations under standard maintenance conditions, on Nematode Growth Medium-lite (NGM-lite, US Biological, Texas, USA) seeded with Escherichia coli strain OP50 at $20^{\circ} \mathrm{C}$, prior to thermal preference and fitness assays. We excluded the N2 strain from our analysis because it shows signs of behavioral adaptation to laboratory conditions [45-48], but we present fitness results for N2 in Additional file 1: Fig. S1.

Thermal preference was assayed as previously described [45]. Briefly, age-synchronized populations of final larval stage worms (L4), reared at $20^{\circ} \mathrm{C}$, were applied to thermal gels [NGM-lite in plastic frames $(10.2 \times 17.5 \times 0.5 \mathrm{~cm})$ seeded with $E$. coli strain OP50] on stable linear thermal gradients $\left(10.5^{\circ} \mathrm{C}-29^{\circ} \mathrm{C}\right)$ at a starting point corresponding to $24^{\circ} \mathrm{C}$. The positions of individual worms were scored after one hour. The temperature chosen by each individual was then estimated from its position on the thermal gradient using a linear model that relates gradient position to temperature. Results were analyzed using analysis of variance (ANOVA) with isolate as the main effect and replicate as a random nested effect. Standard errors were calculated from the model, with replicate as the unit of sampling variation, using a least-square means approach. Differences in thermal preferences among isolates were evaluated using Tukey's HSD, $\alpha=0.05$. All analyses were performed in JMP 4.0 (SAS Institute, Cary, NC, USA).

Fitness (LRS and $r$ ) was assayed at seven temperatures $\left(10^{\circ} \mathrm{C}, 12^{\circ} \mathrm{C}, 14^{\circ} \mathrm{C}, 15^{\circ} \mathrm{C}, 20^{\circ} \mathrm{C}, 23^{\circ} \mathrm{C}\right.$, and $\left.25^{\circ} \mathrm{C}\right)$ in four isolates (CB4854, CB4856, CB4857, PX174) with extreme thermal preferences. Subpopulations of each isolate were allowed to acclimate to the assay temperature for at least two generations prior to use in fitness assays. Individual L4 hermaphrodites, reared from eggs laid by 30 adults within a 3 -h period, were transferred to individual Petri dishes $(35 \times 15 \mathrm{~mm})$ containing NGM-lite seeded with OP50 and incubated at the assay temperature. Reproductively active individuals were subsequently transferred to new dishes at 24-hour intervals. At the highest temperatures worms were transferred more frequently to prevent offspring overcrowding. Offspring produced during each $24-\mathrm{h}$ period were counted at maturity. LRS was calculated as total lifetime fecundity at each temperature and $r$ was calculated from, $\Sigma e^{-}$ ${ }^{r x} l_{x} m_{x}=1$ where $l_{x}$ is age specific survivorship to day $x$, and $m_{x}$ is the fecundity at day $x$ [39]. Results were analyzed using a full factorial ANOVA with isolate and temperature as main effects (data from $25^{\circ} \mathrm{C}$ were excluded from this analysis because PX174 did not reproduce at this temperature). The isolate-specific effects of temperature on fitness were analyzed using ANOVA with isolate as the main effect at each temperature. Differences among isolates were evaluated using LSMeans Contrasts and Tukey's HSD.

\section{Correspondence between thermal preference and fitness}

To determine the correspondence between preference and the two fitness metrics, each isolate's preference for a given temperature, as indicated by the fraction of worms positioned at that temperature $\left(10^{\circ} \mathrm{C}, 12^{\circ} \mathrm{C}, 14^{\circ} \mathrm{C}\right.$, $15^{\circ} \mathrm{C}, 20^{\circ} \mathrm{C}, 23^{\circ} \mathrm{C}$, and $\left.25^{\circ} \mathrm{C} ; \pm 0.5\right)$ on the thermal gradient was correlated with the fitness estimate associated with each of the seven assayed temperatures. If thermoregulation is effective, then the fraction of worms found at a given temperature will correlate positively and strongly with the fitness at that temperature. This approach takes advantage of information from the shape of each isolate's thermal preference distribution and fitness performance curve (i.e. the convolution of the distributions). Note that this is a within-isolate preferenceperformance measure, as opposed to a between-isolate measure, such as the correlation between $T_{\mathrm{p}}$ and $T_{\max }$ among isolates.

\section{Consequences of thermal preference on average fitness}

To determine the average expected fitness $\left(w_{\text {exp }}\right)$ of worms in a thermal gradient for each isolate, we estimated fitness at temperatures from $9^{\circ} \mathrm{C}-29^{\circ} \mathrm{C}$ via linear interpolation of measured values and integrated these data over the isolate-specific thermal preference frequency distribution. The integral was approximated by summing the product of the temperature-specific fitness measures and the proportion of total individuals displaying a preference to that temperature. To quantify the deficit in fitness between the maximum fitness possible ( $w_{\max }$, if individuals thermoregulate perfectly) and the expected average fitness (based on the actual distribution of $T_{\mathrm{p}}$ ), we calculated the Performance Load as $P L=$ $\left(w_{\max }-w_{\text {exp }}\right) / w_{\max } . P L$ measures the proportional 
reduction in fitness of the average individual in a isolate given the thermal preference distribution of that isolate relative to the maximum observed fitness. $P L$ ranges from 0 to 1 where 0 means that all individuals achieve equal, thus maximum, fitness and 1 means that all but one individual has zero fitness.

\section{Results}

Thermal preferences in $C$. elegans natural isolates

We find that $T_{p}$ varies significantly among natural isolates of $C$. elegans $\left(F_{7,23.87}=13.22, p<0.0001\right)$, with $T_{p}$ ranging from $16.9 \pm 0.3$ to $20.7 \pm 0.5^{\circ} \mathrm{C}$ (mean $\pm \mathrm{SEM}$ ) (Figure 2). Variation among replicates within isolates is also significant $\left(F_{24,7452}=6.52, p<0.001\right)$. However, this among-replicate variance accounts for only $2.4 \%$ of the total variation, suggesting that the significant amongreplicate variation likely reflects the large number of individuals sampled within each replicate (average of 233; 7484 total).

The relative frequency distributions of $T_{p}$ for CB4854, CB4856, CB4857, and PX174, the four isolates for which temperature dependent fitness was also determined, are illustrated in Figure 3 (gray bars). Each isolate has a characteristic $T_{p}$ distribution across the gradient, with

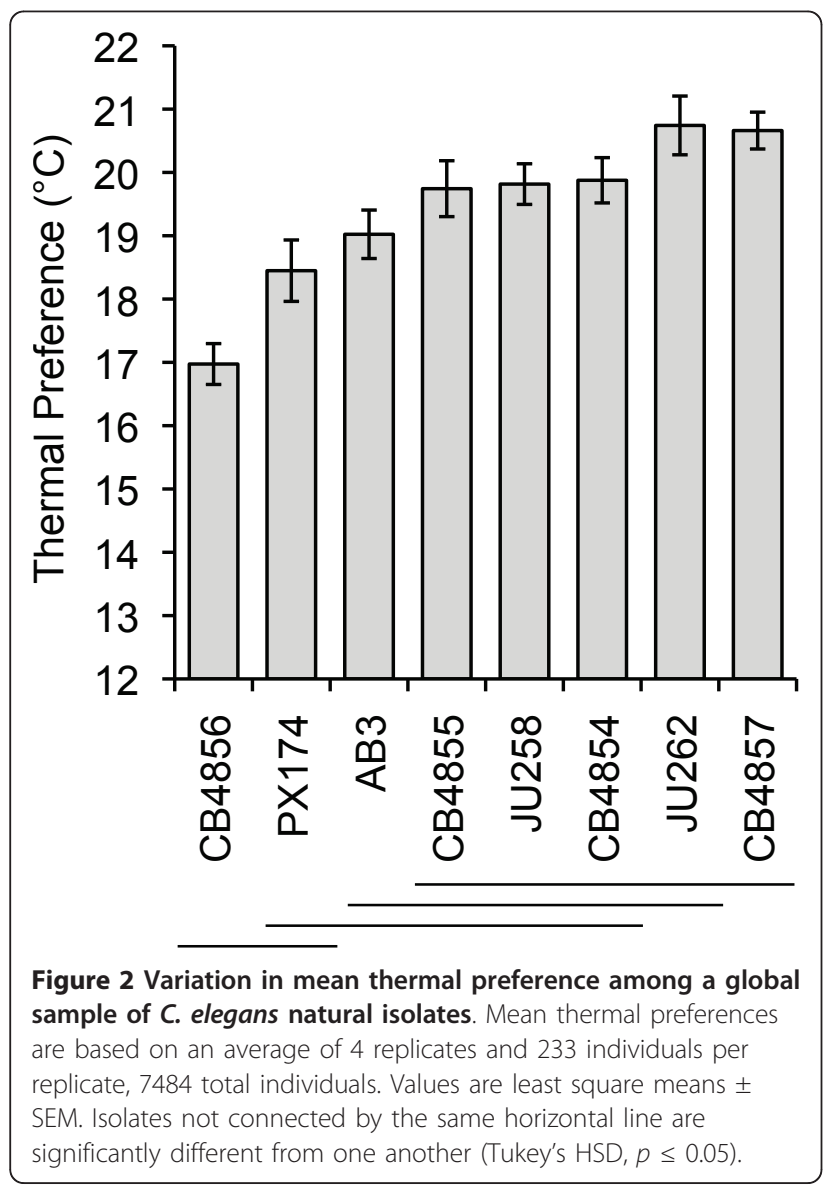

CB4856 tending toward cold temperatures, CB4854 and CB4857 tending toward progressively hotter temperatures, and PX174 dispersing nearly uniformly across most of the gradient but still avoiding the extremes.

\section{Temperature dependent fitness}

The thermal sensitivities of LRS and $r$ vary by isolate (effect of isolate: LRS $F_{3,341}=6.63, p=0.0002 ; r F_{3,341}=$ 27.23, $p<0.0001$; isolate $\mathrm{x}$ temperature interaction: LRS $F_{15,341}=4.97, p<0.0001 ; r F_{15,341}=18.36, p<0.0001$; see also Additional file 2: Fig. S2 and Additional file 3: Fig. S3) but nonetheless show some similarities among isolates. Generally, $r$ increases with temperature up to about $23^{\circ} \mathrm{C}$ before declining steeply for all isolates (Figure 3). LRS increases sharply from $10^{\circ} \mathrm{C}$ to $12^{\circ} \mathrm{C}$, remains relatively high between $12^{\circ} \mathrm{C}$ and $20^{\circ} \mathrm{C}$ (except in CB4857), but then declines rapidly at higher temperatures (Figure 3). CB4857 is unique in that it produces fewer offspring at $14^{\circ} \mathrm{C}$ and $15^{\circ} \mathrm{C}$ than all other isolates (LSMeans Contrast: $14^{\circ} \mathrm{C} F_{1,62}$ $\left.=19.00, p<0.001 ; 15^{\circ} \mathrm{C} F_{1,45}=13.53, p<0.001\right)$. Overall, C. elegans natural isolates are able to maximize LRS, but not $r$, over a broad range of temperatures (Figure 3 ). In other words, $r$ is more thermally sensitive than is LRS.

\section{Coadaptation}

We find that isolates showing marked thermal preference (CB4854, CB4856, CB4847; Figure 3) do prefer temperatures that maximize fitness; however, the aspects of fitness maximized differ depending on whether the isolates have cool versus warm thermal preferences. In CB4856, the isolate with the coolest $T_{p}$ (Figure 2), few worms are found at $25^{\circ} \mathrm{C}$ (Figure $4 \mathrm{~A}$, red circle), a relatively warm temperature at which its reproductive output is low. CB4856 worms more frequently prefer lower temperatures that are associated with higher reproductive output (LRS). Consequently, the correlation between thermal preference and LRS in CB4856 is much higher $\left(r_{c}=0.77, p=0.04\right)$ than that between preference and $r$ $\left(r_{c}=-0.04, p=0.93\right.$; Figure $\left.4 \mathrm{~B}\right)$. In contrast, in two isolates with relatively warm $T_{p}$ (Figure 2), CB4854 and CB4857, thermal preference is correlated tightly with $r$ $\left(r_{c}=0.92, p<0.01\right.$ and $r_{c}=0.97, p<0.01$ respectively) but not LRS $\left(r_{c}=0.13\right.$ and $\left.r_{c}=0.10, \mathrm{p}>0.01\right)$. In PX174, LRS and $r$ show nearly identical, lower correlations with preference (LRS, $r_{c}=0.65, p=0.12 ; r, r_{c}=$ $0.62, p=0.14$ ) likely due to the absence of marked thermal preference behavior in this isolate (i.e. the thermal preference distribution for this isolate is relatively flat). Differential fitness effects also influence correlations between fitness and preference (Figure 5).

\section{Performance cost of imperfect thermoregulation}

The failure of organisms to narrowly prefer and occupy fitness-optimizing temperatures generates a potential 


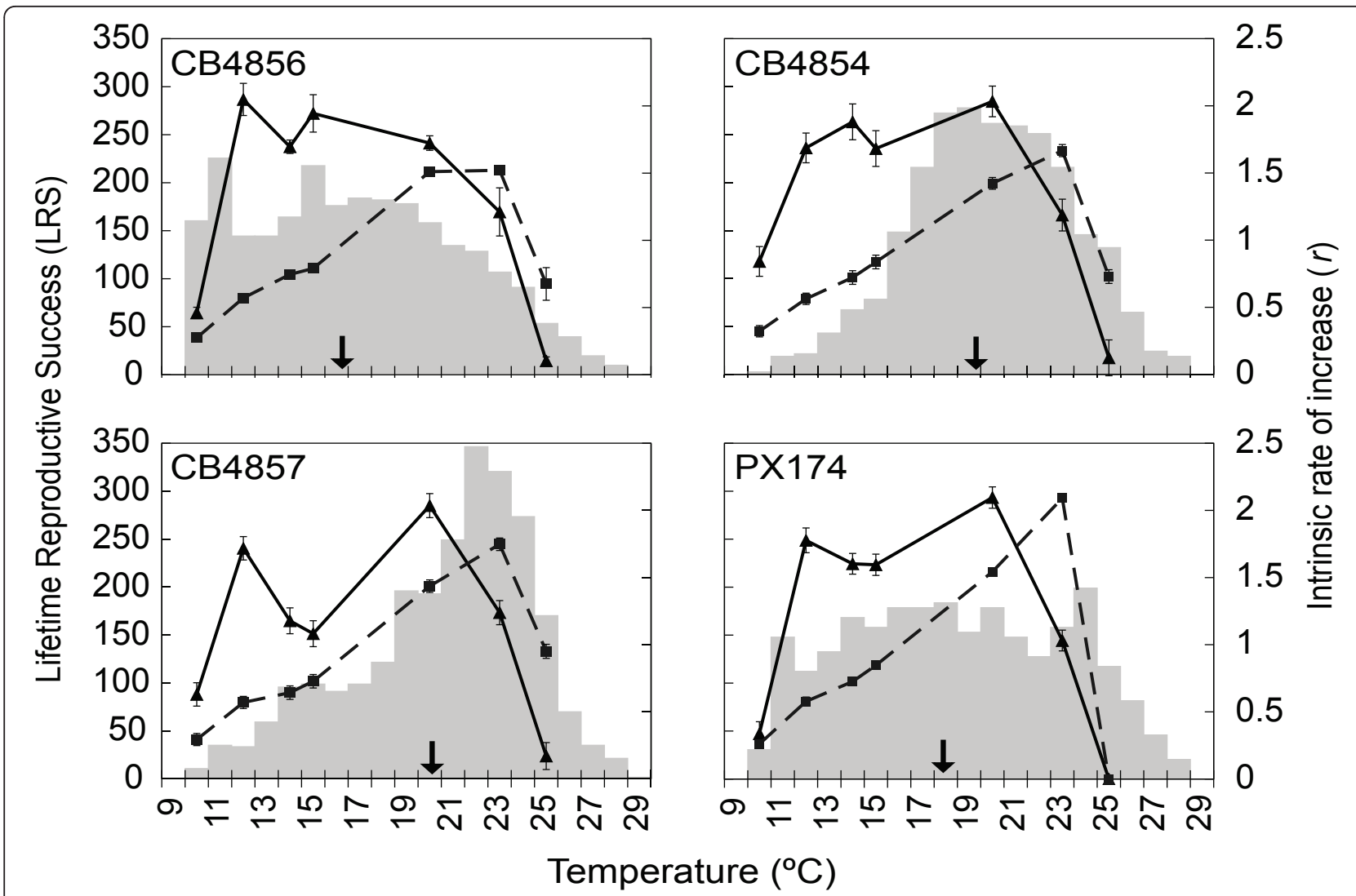

Figure 3 Thermal sensitivity of two measures of fitness, Lifetime Reproductive Success (LRS, solid lines) and intrinsic rate of increase $\left(r\right.$, dashed lines), and the relative distribution of preferred temperatures (grey histograms). $r$ increases with temperature to about $23^{\circ} \mathrm{C}$ before rapidly declining. LRS is relatively high over a relatively broad range of temperatures. Fitness values are least square means \pm SEM, and mean LRS and $r$ at each temperature are calculated from an average of 15 individuals per strain at each temperature, 402 total individuals. Each thermal preference distribution is based on the responses of an average of 1090 individuals. Arrows indicate mean thermal preferences.

"performance load" on mean population fitness, which we calculate here by summing the preference distributions over the thermal fitness curves (thus the load measures the average proportional reduction in fitness relative to the optimum on a scale from 0 to 1 ). Overall, performance loads are moderate to large $(0.25-0.37$ for LRS and 0.28 - 0.50 for $r$; Table 2). For example, PX174 achieves only $50 \%$ of its potential maximal fitness $(r)$ because of sub-optimal thermoregulatory behavior.

\section{Discussion}

Many ectotherms use behavioral adjustments (e.g. in habitat choice, posture, and timing of activity) to regulate body temperatures within preferred ranges $[8,12,49-52]$ thereby avoiding damaging and lethal temperatures as well as maximizing time spent at or near physiologically optimal temperatures. The classical coadaptational hypothesis $[12,18,21]$ predicts that thermal preferences should be centered at or near temperatures that maximize fitness (but see [6]). Moreover, evolutionary shifts in thermal preferences should drive compensatory shifts in the thermal sensitivity of fitness and vice versa $[18,21]$. In this study, we assayed thermal preference and Darwinian fitness in natural isolates of $C$. elegans to test this coadaptational hypothesis.

\section{Coadaptation}

Does thermoregulatory behavior maximize fitness in the isolates of C. elegans studied here? We find that preferred temperatures do correspond with temperatures maximizing fitness, but that the relationship between thermal preference and different aspects of fitness varies among natural isolates of C. elegans (Figures 3, 4). Intraspecific variation in thermal preference-fitness relationships is not predicted by the classical preference-fitness coadaptation hypothesis. Whereas the coadaptation hypothesis predicts that differences in $T_{p}$ among populations should be accompanied by corresponding shifts in $T_{\max }$ (Figure 1A), in our data, fitness curves are not systematically shifted such that $T_{p}$ consistently corresponds with $T_{\max }$ of either $r$ or LRS. Rather, the isolate with the 


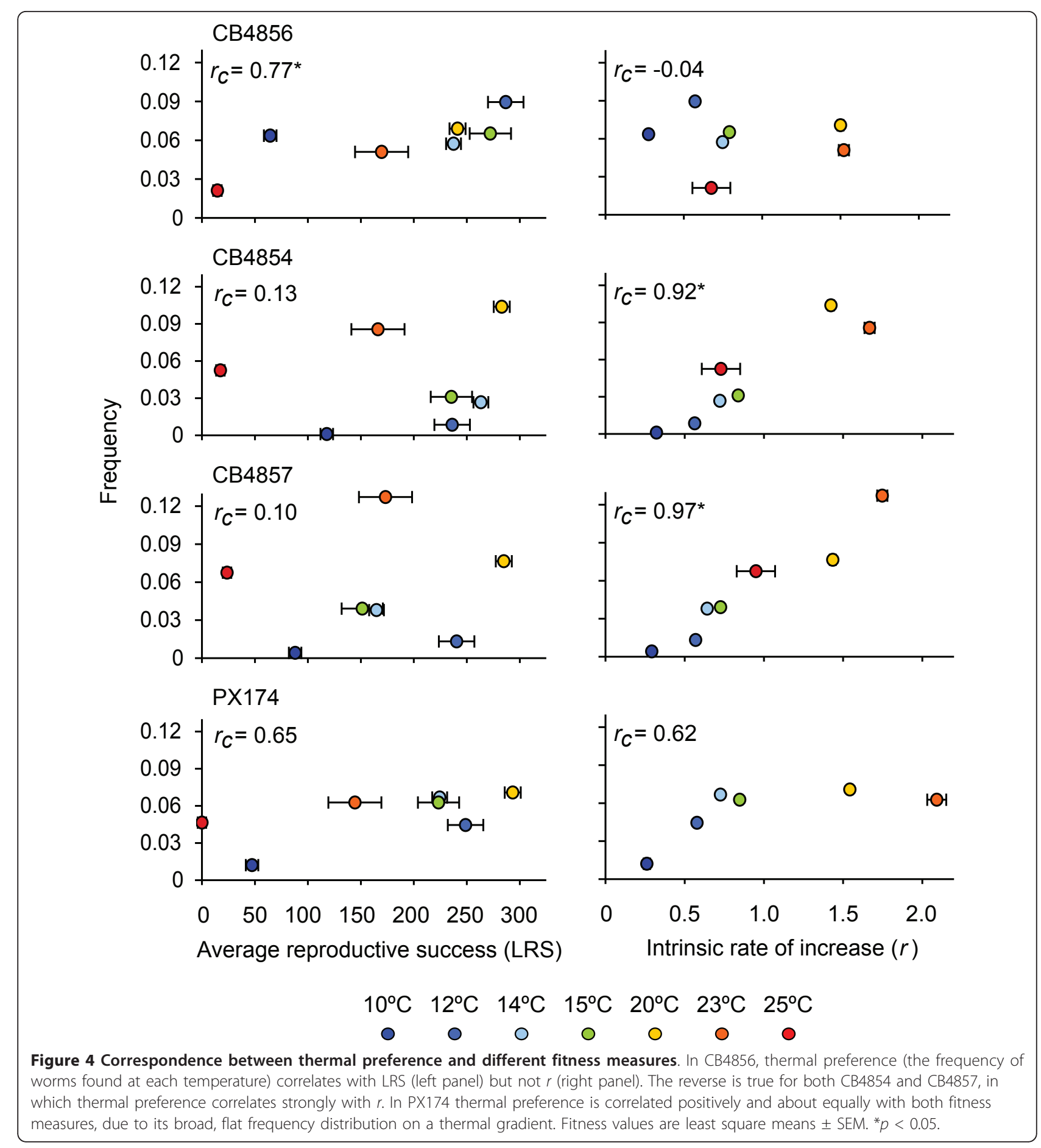

coolest $T_{p}$ favors LRS, while the two isolates preferring a warmer $T_{p}$ (CB4854 and CB4857) favor $r$. Under these circumstances it is not surprising that isolates with high $T_{\mathrm{p}}$ maximize $r$ rather than LRS and vice versa due to the negative relationship between generation time and temperature (Figure 1B) [3,7]. We find that correlations between fitness and thermal preference are driven primarily by isolate-specific differences in thermal preference, but the effects of temperature on fitness also vary among isolates. This is most clearly seen in temperature-dependent reproductive rates among isolates, in which cold-seeking CB4856 strongly outperforms hot-seeking CB4857 at cold temperatures and vice versa (Figure 5). Some of the differentiation among isolates 


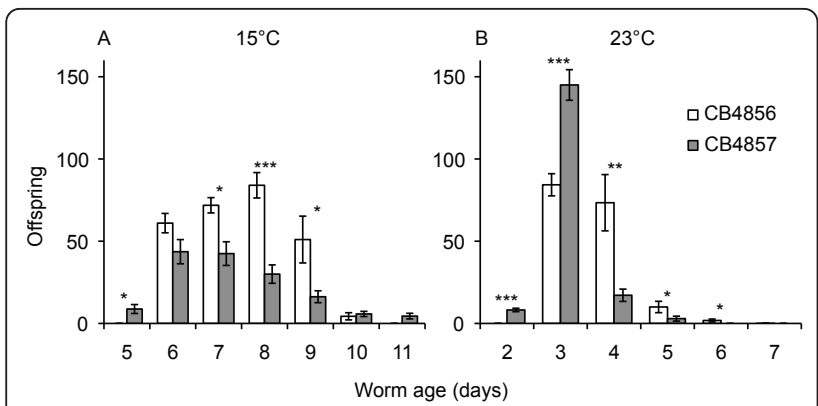

Figure $5 \mathrm{Age}$ and temperature specific offspring production in natural isolates CB4856 and CB4857. A) The cold-seeking isolate CB4856 produces more offspring than the hot-seeking isolate CB4857 at $15^{\circ} \mathrm{C}\left(F_{1,17}=13.42, p=0.0019\right)$. B) In contrast, at $23^{\circ} \mathrm{C}$ LRS does not differ between CB4856 and CB4857 ( $F_{1,23}=14.52, p=$ $0.8779)$, but $C B 4857$ produces significantly more offspring than CB4856 at ages 2 and 3 days which positively impacts $r$. Differences between strains at each age were analyzed using ANOVA with strain as the main effect. ${ }^{*} p<0.05,{ }^{* *} p<0.001,{ }^{* * *} p<0.0001$.

may be facilitated by the largely self-fertilizing mode of reproduction in C. elegans, which tends to increase linkage disequilibrium across the genome [53,54]. There are obviously too few isolates here to definitely define new temperature-fitness rules within this species, but these data strongly suggest that preference-fitness relationships are more complicated than predicted by the classical coadaptation hypothesis.

The optimization of different aspects of fitness under different ecological and/or demographic conditions is predicted by life history theory $[32,33,35]$. Specifically, total offspring production, $R_{o}$ or LRS, should be optimized in stable populations where population size is regulated by density-dependent factors, whereas the intrinsic rate of increase, $r$, should be optimized in density-independent populations where natural selection should favor early reproduction [32,33,35,55]. Therefore, if the coadaptation hypothesis is indeed correct, different components of fitness (e.g. total reproduction versus rate of reproduction) might have been under selection

Table 2 Average expected fitness for each isolate calculated by integrating temperature-dependent fitness measures over the observed thermal preference distributions ("Obs.") compared to the maximum fitness expected is all individuals chose the single best temperature ("Max.")

\begin{tabular}{lllllll}
\hline & \multicolumn{6}{l}{ LRS } \\
\cline { 2 - 7 } Isolate & Obs. & Max. & $\boldsymbol{P L}$ & Obs. & Max. & $\boldsymbol{P L}$ \\
\hline CB4857 & 178 & 285 & 0.37 & 1.25 & 1.75 & 0.29 \\
PX174 & 192 & 293 & 0.34 & 1.04 & 2.09 & 0.50 \\
CB4856 & 211 & 287 & 0.26 & 0.95 & 1.52 & 0.38 \\
CB4854 & 213 & 285 & 0.25 & 1.20 & 1.67 & 0.28 \\
\hline
\end{tabular}

The relative difference between these yields the Performance Load $(P L)$. in different isolates of $C$. elegans. The specific structure of these predictions is likely to benefit from more detailed models of the relationship between metabolism and population dynamics (e.g. [5]).

It is almost certainly true, however, that the evolution of thermal preference-fitness relationships is also influenced by interacting genetic, genomic, physiological, ecological, and environmental factors. For example, important life history traits and genetic correlations between these traits (e.g. age at maturity, egg number, and egg size, and the genetic control of phenotypic plasticity) are temperature-dependent in $C$. elegans [43,56-58]. Moreover, soil nematodes live in highly dynamic thermal environments [59-61]; and nematode community structure is both complex [59] and strongly influenced by temperature [62-65]. Additionally, the impact of temperature on performance may differ depending on physiological context and resource availability [66]. In any case, the fact that Performance Loads are fairly high in all C. elegans isolates (Table 2) suggests that $T_{p}$ is not strongly optimized in this species, and possibly reflects the effects of complex ecological, environmental, and genetic interactions on the evolution of thermal preference-fitness relationships. Thus, while we are able to robustly measure the effect of temperature of various components of fitness in the laboratory environment, true fitness in nature awaits measurement in the field.

\section{Fitness}

Although the effects of temperature on fitness vary among isolates of C. elegans (Figures 3, S2, S3) (see also $[44,67])$, this species can generally be described as a "Jack of all temperatures" [68] in terms of LRS. The isolates studied here produce large numbers of offspring $(\geq$ $75 \%$ of maximal production) over up to $64 \%$ (CB4854) of their reproductive temperature range $\left(9^{\circ} \mathrm{C}\right.$ to $26^{\circ} \mathrm{C}$, herein). Caenorhabditis briggsae, an androdioecious sister species to $C$. elegans, has similarly high offspring production ( $\geq 75 \%$ of maximal production) over $63 \%$ of its reproductive temperature range [69]. However, $C$. briggsae reproduces at a warmer range of temperatures than C. elegans $\left(14^{\circ} \mathrm{C}\right.$ to $30^{\circ} \mathrm{C}$; [69]).

The thermal sensitivity of reproductive output in $C$. briggsae appears to vary with latitude; isolates of tropical origin produce more offspring at high temperatures than do isolates from temperate regions [69]. This pattern is not evident in C. elegans; the lowest latitude isolate we studied (CB4856) does not produce more offspring at high temperatures than do other isolates. There is some evidence, however, that thermal preference varies with latitude in C. elegans $\left(r^{2}=0.60, \mathrm{p}=\right.$ 0.11 ); this suggestive result is entirely driven by CB4856. To date, too few isolates of C. elegans and of C. briggsae 
from geographically diverse, well-characterized collections (i.e. known microclimate and elevation) have been characterized for both thermal preference and temperature dependent fitness to define relationships among thermal preference, fitness, and latitude, or other ecologically relevant clines.

\section{Behavioral variation}

Thermal preference behavior has been studied in C. elegans for more than 30 years [70] and has led to advances in the fields of genetics [71-76], neuroscience [77-80], and the study of memory and learning $[74,78,81]$. Even so, findings from many of these studies are somewhat problematic because seemingly conflicting results have been obtained by different laboratories, apparently driven in part by sensitivity to environmental conditions such as nutritional state and cultivation temperature (e.g. $[45,74,82])$. Thermal gradient steepness can also influence thermal preference behavior in some isolates [83]. The standard laboratory strain N2 only displays typical thermal preference behaviors on gradients $<1^{\circ} \mathrm{C} / \mathrm{cm}$, whereas natural isolates of $C$. elegans, such as those assayed here, are less sensitive to gradient steepness [83]. Here, we assayed thermal preference in eight isolates of $C$. elegans, under identical experimental conditions. Thus, our data clearly illustrate that thermal preference behavior varies significantly among natural isolates in C. elegans (see also $[45,83]$ ). Environmentdependent and isolate-specific variation in thermal preference behavior might be informative from an evolutionary perspective because a behavior with such important effects on fitness might be fine tuned to be sensitive to a number of possible environmental cues. In fact, it would be surprising if we did not find variation in this important behavior given the large potential fitness effects of thermal preference behavior and the fact that $C$. elegans populations are found around the world in different climates. Using genetic differentiation among natural isolates as means of probing this system [84] should help to distinguish evolutionary signal from noise $[45,83]$. However, our results show that interpretation of natural variation, and probably any variation in this trait, must be performed in the context of the ecological causes and consequences of that variation.

\section{Conclusions}

Most studies of the coadaptation of thermal preference and fitness have examined only performance traits and not Darwinian fitness per se. Here we show that thermal preferences can indeed correspond with temperatures maximizing Darwinian fitness in C. elegans, but not as predicted by the coadaptation hypothesis. We find that the relationship between thermal preference and fitness varies among isolates such that isolates that prefer relatively warm temperatures, CB4854 and CB4857, maximize the timing of offspring production $(r)$ and the isolate that prefers a cooler temperature, CB4856, maximizes offspring number (LRS). Thus, we demonstrate that preference-fitness relationships can be more complex that predicted by current theory. Our results also demonstrate that the choice of fitness measure can have a large effect on the interpretation of the coadaptedness of thermal preference and fitness: had we measured only $r$, for instance, we would have concluded that thermal preferences were not correlated with fitness. Finally, despite the tight correlations between thermal preference and specific measures of fitness, the isolates examined here still demonstrate substantial performance loads caused by imprecision of individual preference behavior. Coupling this individual variation with other known external environmental drivers such as rearing temperature (e.g. $[70,83])$ and potential unknown temperature correlates such as predation risk and inter-specific competition suggests that co-adaptation of $T_{\mathrm{p}}$ and thermal sensitivity of fitness is likely to depend on overall interactions involving ecology, environmental experience, behavior and fitness.

\section{Additional material}

Additional file 1: Fig. S1. Temperature-dependent fitness response in the standard lab strain N2.

Additional file 2: Fig. S2. Temperature dependence of Lifetime Reproductive Success (LRS) in four strains of C. elegans.

Additional file 3: Fig. S3. Temperature dependence of the intrinsic rate of increase $(r)$ in four strains of $C$. elegans.

\section{Acknowledgements}

We thank Christina Cooke for lab assistance and Van Savage and three anonymous reviewers for helpful input on the manuscript. This work was supported by the National Science Foundation (IBN-0416205 to PCP and IOB-011684 to RBH) and National Institutes of Health (5F32HD055057 to JLA), and by materials support from the Reliance Steel and Aluminum Co.

\section{Author details}

${ }^{1}$ Center for Ecology and Evolutionary Biology, University of Oregon, Eugene, OR 97402, USA. ²Department of Biology, University of Texas at Arlington, Arlington, TX 76019, USA. ${ }^{3}$ Department of Biology, University of Washington, Seattle, WA 98195, USA. ${ }^{4}$ Department of Zoology, University of Florida, Gainesville, FL 32611, USA.

Authors' contributions

Study designed by PCP, RBH, LA, and JLA. Experiments performed by $L A$ $J \mathrm{~A}$, and BE. Data analyzed by JLA. The manuscript was written by $J$ A, LA, $\mathrm{RBH}$, and PCP. All authors read and approved the final manuscript.

Received: 21 April 2011 Accepted: 6 June 2011 Published: 6 June 2011

\section{References}

1. Fry FEJ: Effects of the environment on animal activity. Univ Toronto Stud, Biol Ser no 55 1947, 68:1-62.

2. Bennett AF: The thermal dependence of lizard behaviour. Anim Behav 1980, 28:752-762. 
3. Huey RB, Berrigan D: Temperature, demography, and ectotherm fitness. Am Nat 2001, 158:204-210.

4. Angilletta MJ: Thermal Adaptation: A Theoretical and Empirical Synthesis Oxford: Oxford University Press; 2009.

5. Dell Al, Pawar S, Savage VM: Systematic variation in the temperature dependence of physiological and ecological traits. Proc Natl Acad Sci USA 2011.

6. Martin TL, Huey RB: Why "suboptimal" is optimal: Jensen's inequality and ectotherm thermal preferences. Am Nat 2008, 171:E102-E118.

7. Savage VM, Gillooly JF, Brown JH, West GB, Charnov EL: Effects of body size and temperature on population growth. Am Nat 2004, 163:429-441.

8. Stevenson RD: The relative importance of behavioral and physiological adjustments controlling body-temperature in terrestrial ectotherms. Am Nat 1985, 126:362-386.

9. Heinrich B: The Hot-blooded Insects: Strategies and Mechanisms of Thermoregulation Cambridge, MA: Harvard University Press; 1993.

10. Kingsolver JG, Watt WB: Thermoregulatory strategies in Colias butterflies: Thermal stress and the limits to adaptation in temporally varying environments. Am Nat 1983, 121:32-55.

11. Grant BW, Dunham AW: Thermally imposed time constraints on the activity of desert lizard Sceloporus merriami. Ecology 1988, 69:167-176.

12. Cowles RB, Bogert CM: A preliminary study of the thermal requirements of desert reptiles. Bull Am Mus Nat Hist 1944, 83:261-296.

13. Christian KA, Tracy CR: The effect of the thermal environment on the ability of hatchling Galapagos land iguanas to avoid predation during dispersal. Oecologia 1981, 49:218-223.

14. Huey RB: Natural variation in body temperature and physiological performance in a lizard. In Advances in Herpetology and Evolutionary Biology: Essays in Honor of Ernest E. Williams. Edited by: Rhodin AGJ, Miyata K. Cambridge, MA: Museum of Comparative Zoology; 1983:484-490.

15. Waldschmidt S, Tracy CR: Interactions between a lizard and its thermal environment: Implications for sprint performance and space utilization in the lizard Uta stansburiana. Ecology 1983, 64:476-484.

16. Hertz PE, Huey RB, Stevenson RD: Evaluating temperature regulation by field-active ectotherms: The fallacy of the inappropriate question. Am Nat 1993, 142:796-818

17. Huey RB, Hertz PE, Sinervo B: Behavioral drive versus behavioral inertia in evolution: A null model approach. Am Nat 2003, 161:357-366.

18. Huey RB, Bennett AF: Phylogenetic studies of coadaptation: Preferred temperatures versus optimal performance temperatures of lizards. Evolution 1987, 41:1098-1115.

19. Beitinger TL, Fitzpatrick LC: Physiological and ecological correlates of preferred temperature in fish. Am Zool 1979, 19:319-329.

20. Bennett AF: Evolution of the control of body temperature: Is warmer better? In Comparative Physiology: Life in Water and on Land. Edited by: Dejours P, Taylor CR, Weibel ER. Padova: Liviana Press; 1987:421-431.

21. Angilletta MJ, Bennett AF, Guderley H, Navas CA, Seebacher F, Wilson RS: Coadaptation: A unifying principle in evolutionary thermal biology. Physiol Biochem Zool 2006, 79:282-294.

22. Licht PE, Dawson WR, Shoemaker VH, Main AR: Observations on the thermal relations of Western Australian lizards. Copeia 1966, 97-110

23. Dawson WR: On the physiological significance of the preferred body temperatures of reptiles. In Perspectives of Biophysical Ecology. Edited by: Gates DM, Schmerl R. New York: Springer-Verlag; 1975:443-473.

24. Angilletta MJ, Hill T, Robson MA: Is physiological performance optimized by thermoregulatory behavior?: A case study of the eastern fence lizard, Sceloporus undulatus. J Therm Biol 2002, 27:199-204.

25. Bartholomew GA: Interaction of physiology and behavior under natural conditions. In The Galápagos. Edited by: Bowman Rl. Berkeley: University of California Press; 1966:39-45.

26. Huey RB, Stevenson RD: Integrating thermal physiology and ecology of ectotherms: A discussion of approaches. Am Zool 1979, 19:357-366.

27. Arnold SJ: Morphology, performance and fitness. Am Zool 1983, 23:347-361.

28. Haldane JBS: The effect of variation of fitness. Am Nat 1937, 71:337-349.

29. Crow JF: Genetic loads and the cost of natural selection. In Mathematical Topics in Population Genetics. Edited by: Kojima K. Berlin: Springer-Verlag; 1970:128-177.

30. Cole LC: The population consequences of life history phenomena. $Q$ Rev Biol 1954, 29:103-137.
31. Travis J, Henrich S: Some problems in estimating the intensity of selection through fertility differences in natural and experimental populations. Evolution 1986, 40:786-790.

32. Roff DA: The Evolution of Life Histories: Theory and Analysis New York: Chapman \& Hall; 1992

33. Stearns SC: The Evolution of Life Histories Oxford: Oxford University Press; 1992.

34. Kozlowski J: Measuring fitness in life-history studies. Trends Ecol Evol 1993, 8:84-85

35. Charlesworth B: Evolution in Age-structured Populations. 2 edition. Cambridge: Cambridge University Press; 1994.

36. Stiernagle T: Maintenance of C. elegans. In C. elegans: A practical approach. Edited by: Hope I. Oxford: Oxford University Press; 1999:51-67.

37. Hodgkin J, Barnes TM: More is not better: Brood size and population growth in a self-fertilizing nematode. Proc R Soc Lond B Biol Sci 1991, 246:19-24

38. Keightley PD, Caballero A: Genomic mutation rates for lifetime reproductive output and lifespan in Caenorhabditis elegans. Proc Nat Acad Sci USA 1997, 94:3823-3827.

39. Vassilieva LL, Lynch M: The rate of spontaneous mutation for life-history traits in Caenorhabditis elegans. Genetics 1999, 151:119-129.

40. Estes S, Ajie BC, Lynch M, Phillips PC: Spontaneous mutational correlations for life-history, morphological and behavioral characters in Caenorhabditis elegans. Genetics 2005, 170:645-653.

41. Baer CF, Phillips N, Ostrow D, Avalos A, Blanton D, Boggs A, Keller T, Levy L, Mezerhane E: Cumulative effects of spontaneous mutations for fitness in Caenorhabditis: Role of genotype, environment and stress. Genetics 2006, 174:1387-1395

42. Byerly L, Cassada RC, Russell RL: The life cycle of the nematode Caenorhabditis elegans: I. Wild-type growth and reproduction. Dev Biol 1976, 51:23-33.

43. Gutteling EW, Riksen JAG, Bakker J, Kammenga JE: Mapping phenotypic plasticity and genotype-environment interactions affecting life-history traits in Caenorhabditis elegans. Heredity 2007, 98:28-37.

44. Harvey SC, Viney ME: Thermal variation reveals natural variation between isolates of Caenorhabditis elegans. J Exp Zool B Mol Dev Evol 2007. 308B:409-416.

45. Anderson JL, Albergotti L, Proulx S, Peden C, Huey RB, Phillips PC: Thermal preference of Caenorhabditis elegans: A null model and empirical tests. J Exp Biol 2007, 210:3107-3116.

46. McGrath PT, Rockman MV, Zimmer M, Jang H, Macosko EZ, Kruglyak L Bargmann Cl: Quantitative mapping of a digenic behavioral trait implicates globin variation in C. elegans sensory behaviors. Neuron 2009, 61:692-699.

47. Weber KP, De S, Kozarewa I Turner DJ, Babu MM, de Bono M: Whole genome sequencing highlights genetic changes associated with laboratory domestication of C. elegans. PLOS ONE 2010, 5:e13922.

48. Gaertner BE, Phillips PC: Caenorhabditis elegans as a platform for molecular quantitative genetics and the systems biology of natural variation. Genet Res 2010, 92:331-348.

49. Heath JE: Temperature regulation and diurnal activity in horned lizards. Univ Calif Publ Zool 1965, 64:97-136.

50. Huey RB, Pianka ER, Hoffman J: Seasonal variation in thermoregulatory behavior and body temperature of diurnal Kalahari lizards. Ecology 1977, 58:1066-1075.

51. Christian K, Tracy CR, Porter WP: Seasonal shifts in body temperature and use of microhabitats by Galapagos land iguanas (Conolophus pallidus). Ecology 1983, 64:463-468.

52. Kingsolver JG: Evolution and coadaptation of thermoregulatory behavior and wing pigmentation pattern in Pierid butterflies. Evolution 1987, 41:472-490.

53. Cutter AD: Nucleotide polymorphism and linkage disequilibrium in wild populations of the partial selfer Caenorhabditis elegans. Genetics 2006, 172:171-184

54. Rockman MV, Kruglyak L: Recombinational landscape and population genomics of Caenorhabditis elegans. PLoS Genet 2009, 5:e1000419.

55. Fisher RA: The genetical theory of natural selection Oxford: Clarendon Press; 1930.

56. Gutteling EW, Doroszuk A, Riksen JAG, Prokop Z, Reszka J, Kammenga JE: Environmental influence on the genetic correlations between life-history traits in Caenorhabditis elegans. Heredity 2007, 98:206-213. 
57. Voorhies V: Bergmann size clines: A simple explanation for their occurrence in ectotherms. Evolution 1996, 50:1259-1264.

58. Kammenga JE, Doroszuk A, Riksen JAG, Hazendonk E, Spiridon L, Petrescu AJ, Tijsterman M, Plasterk RHA, Bakker J: A Caenorhabditis elegans wild type defies the temperature-size rule owing to a single nucleotide polymorphism in tra-3. PLoS Genet: e34 2007.

59. Anderson RV, Coleman DC: Nematode temperature responses: A niche dimension in populations of bacterial-feeding nematodes. I Nematol 1982, 14:69-76.

60. Feder ME: Necrotic fruit: A novel model system for thermal ecologists. $J$ Therm Biol 1997, 22:1-9.

61. Jones JS, Coyne JA, Partridge L: Estimation of the thermal niche of Drosophila melanogaster using a temperature-sensitive mutation. Am Nat 1987, 130:83-90.

62. Freckman DW, Virginia RA: Low-diversity Antarctic soil nematode communities: Distribution and response to disturbance. Ecology 1997, 78:363-369.

63. Ruess $\mathrm{L}$, Michelsen $\mathrm{A}$, Jonasson S: Simulated climate change in subarctic soils: Responses in nematode species composition and dominance structure. Nematology 1999, 1:513-526.

64. Hoschitz M, Kaufmann R: Soil nematode communities of Alpine summitssite differentiation and microclimatic influences. Pedobiologia 2004, 48:313-320.

65. Pen-Mouratov $S$, He XL, Steinberger $Y$ : Spatial distribution and trophic diversity of nematode populations under Acacia raddiana along a temperature gradient in the Negev Desert ecosystem. J Arid Environ 2004, 56:339-355.

66. Brett JR: Energetic responses of salmon to temperature. A study of some thermal relations in physiology and freshwater ecology of sockeye salmon (Oncorhynchus nerka). Am Zool 1971, 11(1):99-113.

67. Kader NA, Côté MG: Isolation, identification and characterization of some strains of Caenorhabditis elegans (Maupas, 1900) from Quebec. Fund Appl Nematol 1996, 19:381-389.

68. Huey RB, Hertz PE: Is a Jack-of-all-temperatures a master of none? Evolution 1984, 38:441-444.

69. Prasad A, Croydon-Sugarman MJ, Murray RL, Cutter AD: Temperaturedependent fecundity associates with latitude in Caenorhabditis briggsae. Evolution 2010, 65:52-63.

70. Hedgecock EM, Russell RL: Normal and mutant thermotaxis in the nematode Caenorhabditis elegans. Proc Natl Acad Sci USA 1975, 72:4061-4065

71. Cassata G, Kagoshima H, Andachi Y, Kohara Y, Durrenberger MB, Hall DH, Burglin TR: The LIM homeobox gene ceh-14 confers thermosensory function to the AFD neurons in Caenorhabditis elegans. Neuron 2000, 25:587-597.

72. Colosimo ME, Brown A, Mukhopadhyay S, Gabel C, Lanjuin AE, Samuel ADT, Sengupta P: Identification of thermosensory and olfactory neuronspecific genes via expression profiling of single neuron types. Curr Biol 2004, 14:2245-2251.

73. Satterlee JS, Ryu WS, Sengupta P: The CMK-1 CaMKI and the TAX-4 cyclic nucleotide-gated channel regulate thermosensory neuron gene expression and function in C. elegans. Curr Biol 2004, 14:62-68

74. Mohri A, Kodama E, Kimura KD, Koike M, Mizuno T, Mori I: Genetic control of temperature preference in the nematode Caenorhabditis elegans. Genetics 2005, 169:1437-1450.

75. Inada $\mathrm{H}$, Ito $\mathrm{H}$, Satterlee J, Sengupta P, Matsumoto K, Mori I: Identification of guanylyl cyclases that function in thermosensory neurons of Caenorhabditis elegans. Genetics 2006, 172:2239-2252.

76. Tanizawa Y, Kuhara A, Inada H, Kodama E, Mizuno T, Mori I: Inositol monophosphatase regulates localization of synaptic components and behavior in the mature nervous system of C. elegans. Genes Dev 2006 20:3296-3310.

77. Mori I, Ohshima Y: Neural regulation of thermotaxis in Caenorhabditis elegans. Nature 1995, 376:344-348.

78. Samuel ADT, Silva RA, Murthy VN: Synaptic activity of the AFD neuron in Caenorhabditis elegans correlates with thermotactic memory. I Neurosci 2003, 23:373-376.

79. Zariwala HA, Miller AC, Faumont S, Lockery SR: Step response analysis of thermotaxis in Caenorhabditis elegans. J Neurosci 2003, 23:4369-4377.
80. Clark DA, Biron D, Sengupta P, Samuel ADT: The AFD sensory neurons encode multiple functions underlying thermotactic behavior in Caenorhabditis elegans. J Neurosci 2006, 26:7444-7451.

81. Kodama E, Kuhara A, Mohri-Shiomi A, Kimura KD, Okumura M, Tomioka M, lino Y, Mori I: Insulin-like signaling and the neural circuit for integrative behavior in C. elegans. Genes Dev 2006, 20:2955-2960.

82. Ito $\mathrm{H}$, Inada $\mathrm{H}$, Mori l: Quantitative analysis of thermotaxis in the nematode Caenorhabditis elegans. J Neurosci Methods 2006, 154:45-52.

83. Jurado $P$, Kodama E, Tanizawa Y, Mori I: Distinct thermal migration behaviors in response to different thermal gradients in Caenorhabditis elegans. Genes Brain Behav 2010, 9:120-127.

84. Kammenga JE, Phillips PC, De Bono M, Doroszuk A: Beyond induced mutants: Using worms to study natural variation in genetic pathways. Trends Genet 2008, 24:178-185.

doi:10.1186/1471-2148-11-157

Cite this article as: Anderson et al:: Does thermoregulatory behavior maximize reproductive fitness of natural isolates of Caenorhabditis elegans?. BMC Evolutionary Biology 2011 11:157.

\section{Submit your next manuscript to BioMed Central and take full advantage of:}

- Convenient online submission

- Thorough peer review

- No space constraints or color figure charges

- Immediate publication on acceptance

- Inclusion in PubMed, CAS, Scopus and Google Scholar

- Research which is freely available for redistribution

Submit your manuscript at www.biomedcentral.com/submit
C Biomed Central 